Contents available at: Sri Lanka Journals Online

\title{
Junk Food Consumption, Physical Activity and Nutritional Status of Adolescent School Children: A Case Study in Ratnapura District of Sri Lanka
}

\author{
U.L.N.S. Ekanayake ${ }^{1}$ and D.G.N.G. Wijesinghe ${ }^{2 *}$ \\ ${ }^{1}$ Postgraduate Institute of Agriculture, University of Peradeniya, Peradeniya, Sri Lanka. \\ ${ }^{2}$ Department of Food Science and Technology, Faculty of Agriculture, University of Peradeniya, Peradeniya, Sri Lanka.
}

\section{ARTICLE INFO}

\section{Article history:}

Received: 31 June 2020

Revised version received: 01 October 2020

Accepted: 05 November 2020

Available online: 1 January 2021

Keywords:

Adolescent school children

BMI

Junk food

Obesity

Physical activity

\section{Citation:}

Ekanayake, U.L.N.S. and Wijesinghe, D.G.N.G. (2021). Junk Food Consumption, Physical Activity and Nutritional Status of Adolescent School Children: A Case Study in Ratnapura District of Sri Lanka. Tropical Agricultural Research, 32(1): 105-113.

DOI: http://doi.org/10.4038/tar.v32i1.8446

Ekanayake, U.L.N.S.

https://orcid.org/0000-0002-9228-2927

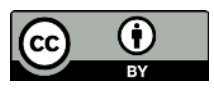

\section{ABSTRACT}

Junk food is rich in fats, sugar, salt and calories. Excess consumption of junk food leads to various health and nutritional disorders. The association between junk food consumption at breakfast of adolescent school children, their physical activity level and BMI status was determined in the current study. A cross-sectional study involving 300 male and female students of the age range 12-14 years from four randomly selected schools in Ratnapura district was conducted in 2019. Information regarding physical activity, breakfast practices and energy expenditure was obtained using a pre-tested questionnaire filled by the students. The criteria recommended by the International Obesity Task Force (IOTF) were used to define obesity and overweight, sex and age-specific body mass index (BMI). The study showed, although $72 \%$ of the students were aware of the unhealthiness of the junk food habit and more than $85 \%$ of the parents were aware and students were knowledgeable about the nutrient facts, $72.7 \%$ consumed it due to the taste and the rest due to its convenience. The frequent junk food consumers at breakfast were more obese $(p=0.002)$ and overweight $(p$ $=0.003$ ) compared to occasional junk food eaters most of whom were in the normal BMI range. A negative correlation was observed between BMI and energy expenditure (Pearson correlation $=-0.49$ ) where a higher BMI was observed with inactive $(\mathrm{p}<0.001)$ or minimally active $(\mathrm{p}<0.002)$ students. A nutritional transition from underweight to overweight and obesity related to junk food consumption is evident from the above data in Ratnapura district of Sri Lanka.

*Corresponding author: wijeng@yahoo.com 


\section{INTRODUCTION}

In the past, overweight and obesity were considered as a health issue mainly associated with high-income countries. However, recently, the incidences of overweight and obesity have been dramatically risen in low- and middle-income countries (World Health Organization, 2014). The nutritional transition in developing countries has shifted people from their traditional diet based on cereals, legumes, vegetable and fruits, to an energydense diet rich in saturated fatty acids, salt and sugar. This is associated with the changes in the socioeconomic status of the society, which has created significant changes in the lifestyle of adults as well as in children.

In addition to changing the dietary patterns, increased time spent in sedentary activities has become a major factor in causing childhood obesity (World Health Organization, 2014). The overweight and obesity have a close relationship with non-communicable diseases such as diabetes, blood pressure, asthma, low back pain and depression, which are rising concerns all over the world (Kearns et al., 2014). The lack of physical activity such as prolonged television viewing, playing computer games, as well as nutritional factors such as consumption of junk food and calorie-dense food and a family history of obesity are the main causes of overweight and obesity among the young individuals (Mistry and Puthussery, 2015). Junk food contains a high energy content that causes a reduction in appetite. Free availability of junk food in the market, low price, attractive advertisements and packaging and the lack of parental awareness are the main causes of children's tendency to consume them(Behzad et al., 2015).

Sri Lanka is a developing country in South Asia with a lower-middle-income status. Jayawardena et al. (2016) reported that the prevalence of overweight and obesity among the adult population in Sri Lanka was $25.2 \%$ and $9.2 \%$ respectively. A study conducted in the urban areas of Colombo, Sri Lanka showed that after the application of Asian BMI cutoffs, the respective prevalence of underweight, normal weight, overweight and obesity were $7.7 \%$, $26.8 \%, \quad 34.3 \%$ and $31.2 \%$, respectively (Somasundaram et al., 2019). It was predicted that overweight will account for $18-40 \%$ of diet-related chronic diseases and $20.9 \%$ of all deaths by 2025 (Popkin et al., 2001). According to the Food and Nutrition Policy of Sri Lanka (2004-2010), the majority of national public health programs and research on children have focused on under nutrition status (Ministry of Healthcare and Nutrition, 2010) while over nutrition problem has not been adequately addressed. Ratnapura district in Sri Lanka consists of wealthy communities compared to many other parts of the country. However, both over nutrition and under nutrition are seen among adolescent school children.

Among the meals consumed during the day, breakfast is an important meal, which supplies an optimum intake of nutrients. Contents of breakfast also have shown a strong relation to the prevalence of overweight and obesity (Fernández Morales et al., 2011). Adolescent school children of 12-14 years of age have shown an increase in overweight and obesity compared to the primary school children (Waters et al., 2008). Furthermore, adolescents can be considered to have a better understanding and are relatively independent on food selection compared to primary children. During the pretesting of the questionnaire, it was found that the study sample consumed junk food mostly during breakfast than in other main meals, the most common reason being the lack of time for parents to prepare breakfast at home. Therefore, the objective of the present research study was to investigate the association of junk food consumption at breakfast and their correlation with the nutritional status and the level of physical activity, of adolescent school children.

\section{METHODOLOGY}

\section{Study design, population and sample}

A cross-sectional study was conducted in September 2019 with students of four mixed schools in the Ratnapura district. They showed a fair representation of all social levels. All students whose ages were in the range of 12-14 years and who were present at the school on the day of the survey were considered as eligible subjects. A total number of 425 students participated in the study. The students were well informed about the purpose of the study and their written consent was obtained prior to the study. A self-guided questionnaire (adapted from Boylan et al., 2017) was requested to be filled by students, which contained questions on behaviour, breakfast and socioeconomic factors. Prior to the preparation of the final questionnaire, an exploratory survey was conducted as a pre-test with randomly selected 25 students to identify different types of junk food consumed and the factors that are likely to influence the consumption of junk food.

\section{Assessment of nutritional status}

The height of the student was measured using a standard scale (Seca 213 Portable stadiometer) to the nearest $0.1 \mathrm{~cm}$ and the weight was measured using an electronic weighing scale (Constant - 
model: $14192-016 \mathrm{~A})$ to the nearest $100 \mathrm{~g}$. The students were positioned with heels, buttocks, back of the chest and back of the head touching the vertical plane of the stadiometer and the head held in the horizontal plane. Calibration was checked with a standard weight after every 25 measurements. The NCHS/CDC (2000) references were used to define nutritional indices (Robert et al., 2002). The criteria recommended by the International Obesity Task Force (IOTF) were used to define obesity and overweight, sex and agespecific body mass index (Hajian-Tilaki and Heidari, 2013; World Health Organization., 2013). Sex-specific BMI-for-age references were used to define categories of nutritional status as underweight $<5^{\text {th }}$ percentile, overweight $>85^{\text {th }}$ to $<95^{\text {th }}$ percentile and obesity $>95^{\text {th }}$ percentile.

\section{Assessment of physical activity}

Lifestyle practices were assessed using a pretested questionnaire adapted from standard PAQC and PAQ-A manual (Kowalski et al., 2004). This questionnaire covered all domains of physical activity including transport, household, fitness and sports, representing light-, moderate- and vigorous-intensity physical activities.

Moderate-intensity physical activities included were the activities such as normal pace walking, brisk walking, recreational swimming, household activities and recreational sports such as volleyball and badminton. Vigorous-intensity physical activities were activities such as stair climbing, jogging, running, cycling and active sports such as basketball. Energy expenditure of physical activities was assigned MET (Metabolic Equivalent for Task) values based on the compendium of physical activity for youth (Ridley et al., 2008; Ainsworth et al., 2011). Moderate-intensity recreational sports were assigned an average MET value equivalent to 4 METs. Vigorous-intensity sports were assigned an average MET value equivalent to 8 METs. Slow walking, normal pace walking and brisk walking was assigned MET values of 2.8, 3.5 and 4.5, respectively, based on modified MET values from the compendium of physical activity for youth (Bauman et al., 2009). The questionnaire allowed the calculation of total energy expenditure per week based on metabolic equivalent (MET-min) values of all types of physical activities reported by each participant. To measure the participant's level of physical activity, the total MET-min/ week was used. The classifications adapted for activity levels in this study were based on two cut-off points of 30 and 60 minutes per day of at least a moderate level of physical activity. The daily 60 minutes of at least a moderate level of physical activity was based on the 2010 physical activity recommendations by the WHO (World Health Organization 2010). This was then converted into three activity categories based on total MET minute /week as follows: Active $>1680$ MET-min per week ( 60 minutes $\times 7$ days $\times 4$ METs). Minimally active category was assigned, if the MET-min /week ranged between 840 (30 minutes $\times 7$ days $\times 4$ METs) and 1680, whereas inactive category was assigned if $<840$ MET-min /week (Kesäniemi et al., 2010).

\section{Junk food consumption}

The term Junk food was used to describe food and drinks low in nutrients (e.g. protein vitamins, minerals and fibre) and high in energy, saturated fat, added sugar and/or added salt with or without other additives. Junk foods contribute to a nutritionally imbalanced diet and regular consumption is known to cause non-communicable diseases in the long run.

According to the results of the pre-tested questionnaire, extensively consumed junk food by the students in the study area included a variety of short eats (e.g. rolls, cutlets, wade, samosa etc.), candies, French fries, different types of sweets and cookies, ice cream, chips and deep-fried street foods like bite mixtures.

The parents' awareness of junk food consumption by their children was obtained from the responses given by student participants.

\section{Data analysis}

Using weight, height and age of children, BMI-forage $\mathrm{z}$ scores were computed to describe underweight, overweight and obesity (de Wilde $e t$ al., 2015). A detailed analysis of data was conducted using IBM SPSS Statistics 20 software. Descriptive data were summarized using standard deviations or percentage and group differences in categorical variables were tested using Pearson's Chi-square test and a $p$ value of $<0.05$ was considered significant. The relationship between BMI and energy expenditure was analysed using the Pearson correlation coefficient.

\section{RESULTS AND DISCUSSION}

\section{General characteristics of the study sample}

Of the 425 students recruited to the study, only 300 students completed the questionnaire. Table 1 illustrates the descriptive data on age, anthropometry and energy expenditure according to gender. 
A significant difference in weight, height and BMI between boys and girls ( $p>0.05)$ was not observed in the study sample. Furthermore, a significant difference in the energy expenditure was also not observed between boys and girls ( $p>0.05)$.

\section{Nutritional status}

According to the BMI status of students, more than half of the students were in the normal BMI range (55\%). Although nearly half of adolescent school children suffered from nutritional issues, obese and overweight conditions were slightly higher (24\%) than underweight condition (21\%). A study conducted in an urban area of Colombo using grade 6-7 school children Wickramasinge et al. (2010) reported that they suffered from obesity or overweight conditions because they were addicted to an inactive lifestyle.

\section{Junk food consumption}

From the pre-test of the survey it was revealed that most students consumed junk food for their breakfast rather than for lunch or dinner. Therefore, the habit of junk food consumption for breakfast was studied in the proper questionnaire.

\section{Consumption of junk food for breakfast}

When students were asked to respond to junk food consumption as an alternative to their breakfast, $22.0 \%$ reported that they consumed junk food 5-6 times per week while the majority (44.7\%) reported that they consumed junk food sometimes (2-3 times per week). The rest of the students (33.3\%) didn't consume junk food as their breakfast. There were two main reasons for consuming junk food by the respondents; firstly, facing a tight schedule with their studies during the day, hence not having enough time to eat a proper meal and secondly, when their parents didn't wake up early enough in the morning to prepare breakfast. Those who did not consume junk food stated that their parents were strictly against the consumption of junk food and hence parents prepared the breakfast for children. According to the literature, a common reason for motivating junk food consumption by students was that most students receive money from their parents to take the morning meal from the cafeteria (Montoye et al., 2013).

The factors affecting the consumption of junk food among adolescent school children were described in Figure 1. The majority of participants who consumed junk food believed that junk food provides them with a pleasant feeling due to their deliciousness. When the students were asked to select the factor that influenced them in selecting the type of junk food, $73 \%$ opted for taste, $13.7 \%$ for saving time, $7.7 \%$ for the low price and $6.0 \%$ for other reasons. According to literature, taste is the most critically influencing factor because students get addicted to the artificial taste of junk food (Askari Majabadi et al., 2016). Breakfast skipping was associated with gaining weight, obesity and addiction to unhealthy dietary habits including more frequent junk foods (Tin et al., 2011). The students also considered convenience of junk food as an attraction to them: they were relatively affordable and quick and easy to consume. Furthermore, participants mentioned that the variety of flavours and colours of junk foods are other factors motivating consumption. Additionally, social norms and friendship were also expressed as motivating factors for junk food consumption. Some participants stated that they ate junk food unwillingly, but simply as a measure of social harmony with their friends.

Table 1: Descriptive data on age, anthropometry and energy expenditure of the study sample $(n=$ 300)

\begin{tabular}{|c|c|c|c|c|}
\hline \multirow{3}{*}{ Characteristics } & \multicolumn{3}{|c|}{ Mean (SD) } & \multirow{3}{*}{$\mathbf{p}$} \\
\hline & \multirow{2}{*}{ Total } & \multicolumn{2}{|c|}{ Gender } & \\
\hline & & Male & Female & \\
\hline No. of children & 300 & 138 & 162 & - \\
\hline Weight (kg) & $40.09(10.66)$ & $39.67(10.31)$ & 40.45 (10.97) & 0.526 \\
\hline Height (m) & $1.38(0.094)$ & $1.39(0.095)$ & $1.38(0.094)$ & 0.381 \\
\hline Age (years) & $13.40(0.94)$ & $13.26(0.65)$ & $12.85(0.97)$ & 0.372 \\
\hline BMI $\left(\mathrm{kg} / \mathrm{m}^{2}\right)$ & 21.09 (5.44) & $20.72(5.29)$ & $21.40(5.55)$ & 0.279 \\
\hline MET-min & $995.1(10.7)$ & $992.4(10.4)$ & $985.7(10.8)$ & 0.256 \\
\hline
\end{tabular}

SD: standard deviation, p: probability value of Pearson's Chi-square test 
Table 2 illustrates the correlation between junk food consumption for breakfast and the nutritional status of the students.

Majority of obese (76\%) and overweight (67\%) children consumed junk food (the student's response for the junk food consumption as 'sometimes' and 'yes' are combined together) as the morning meal. There was a statistically significant difference between obese, underweight and overweight status with the consumption of junk food for breakfast $(p<0.05)$ indicating that students who consumed a higher amount of junk food for breakfast have a higher BMI than those who consumed junk food very rarely for breakfast. Thus, there was a clear relationship between the junk food consumption at breakfast and BMI among the adolescent students.

\section{Parent's awareness about the junk food consumption of children as reported by students}

An $87 \%$ of the respondents said their parents were aware of their junk food consumption habits. A few students (8\%) said that they didn't have an idea regarding their parent's awareness about their junk food consumption. Other respondents (5\%) said that their parents were unaware of their junk food consumption implying that they consumed it secretly to their parents.

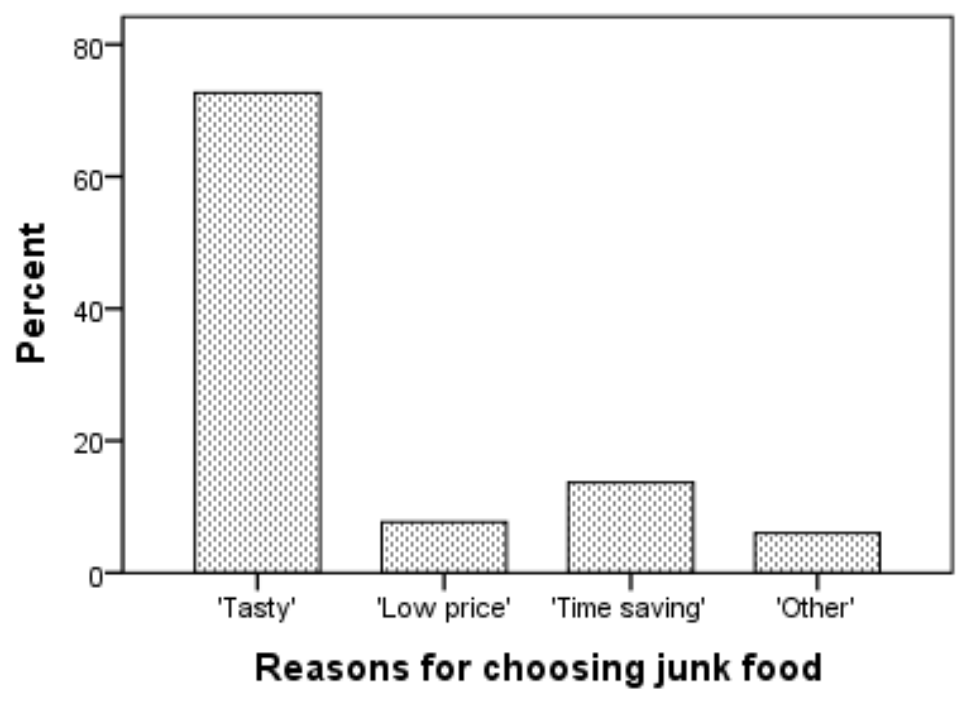

Figure 1: Reasons for choosing junk foods for breakfast by adolescent school children $(n=300)$

Table 2: Association between junk food consumption for breakfast and the nutritional status of adolescent school children

\begin{tabular}{|c|c|c|c|c|}
\hline \multirow{2}{*}{ Nutritional status* } & \multicolumn{2}{|c|}{ Junk food consumption for breakfast \% } & \multirow{2}{*}{ Chi-square } & \multirow{2}{*}{$\mathbf{p}$} \\
\hline & Yes & No & & \\
\hline Obese & 76.0 & 24.0 & 13.5 & 0.0002 \\
\hline Overweight & 66.7 & 33.3 & 13.3 & 0.0003 \\
\hline Normal & 36.6 & 63.4 & 0.62 & 0.4327 \\
\hline Underweight & 23.2 & 76.8 & 11.59 & 0.0007 \\
\hline
\end{tabular}

*Nutritional status categories were according to Asian BMI cut off values. P: Probability value of Pearson's Chi-square $(n=300)$ 


\section{Students' perception of junk food consumption}

Majority of the students (72\%) correctly identified as junk food being not healthy. They were aware that junk foods may lead to depression in teenagers, increase in body weight, impair digestion and increase the risk of heart and kidney diseases and cancer. Few students (28\%) believed that junk food was healthy food good for body functions. Therefore, the adolescent students in this area had fair knowledge about a healthy and a non-healthy diet.

\section{Students' awareness about nutrient facts in the label}

The majority $(54.3 \%)$ of the students mentioned that they check the label containing nutrient facts because they want to know the contents of the food. Some students (34.7\%) only occasionally checked the nutrient fact panel. Due to the fact that they mostly consumed junk food either at school or in the street, a minority of students (11\%) said they didn't check the nutrient contents or ingredients in the label at all. Neuhouser et al. (1999) reported that individuals with a low intake of fat have an idea about nutrition labels. According to Antony and Bhatti (2015) many teenagers had a general idea that junk food is unhealthy but lacked the specific knowledge about the ingredients, preservatives and chemicals used in junk food and their respective safety levels. However, in the present study, awareness of the participants about the ingredients in the label could be considered as satisfactory. The results revealed that the majority of the students agreed to the fact that they were not eating right but they felt that the diet is not of much importance and that they were too busy to think much about food.

\section{Physical activity}

Table 3 indicates that $64.0 \%$ and $35.6 \%$ of inactive students suffered from obesity and overweight, respectively. A higher percentage of obese students were physically inactive compared to overweight or normal students $(\mathrm{p}<0.05)$. Minimally active and inactive groups were combined as "less active" students and accordingly, 40.4\% normal children and $67.6 \%$ underweight children were less active whereas $96.0 \%$ obese and $91.2 \%$ overweight children were less active. According to the results shown in Table 3, a clear relationship could be established between BMI of the students and physical activity level $(\mathrm{p}<0.05)$. Thus, there was a clear relationship between the level of physical activity of students and their BMI. Literature reported a similar, statistically significant relationship between BMI status and the physical activity level among school children aged 14-15 years in Kalutara district (Godakanda et al., 2018).

The scatter plot in Figure 2 indicates a linear association between energy expenditure and BMI value. As shown, there is a negative correlation between BMI and energy expenditure $(r=-0.49, \mathrm{p}$ $=0.000$ ).

Major limitation of this study could be the relatively smaller sample size, the shorter time period used in the assessment of junk food consumption and the qualitative nature of the questionnaire used. Therefore, an in-depth study with quantitative data on lifestyle practices with a larger sample size is warranted to provide a better understanding of the situation existing in the area.

Table 3: Association between physical activity level and nutritional status of adolescent school children

\begin{tabular}{lccccc}
\hline \multirow{2}{*}{ Nutritional status* } & \multicolumn{3}{c}{ Physical Activity level \% } & Chi-square & p \\
\cline { 2 - 4 } & Active & Inactive & Minimally active & & \\
\hline Obese & 4.0 & 64.0 & 32.0 & 44.71 & 0.00001 \\
Overweight & 8.9 & 35.6 & 55.6 & 21.89 & 0.00002 \\
Normal & 59.5 & 9.9 & 30.5 & 24.96 & 0.00001 \\
Underweight & 32.3 & 3.0 & 64.6 & 19.15 & 0.00001 \\
\hline
\end{tabular}

* Nutritional status was according to Asian BMI cut-off values p: probability value of Pearson's Chi-square test; $\mathrm{n}=300$. 


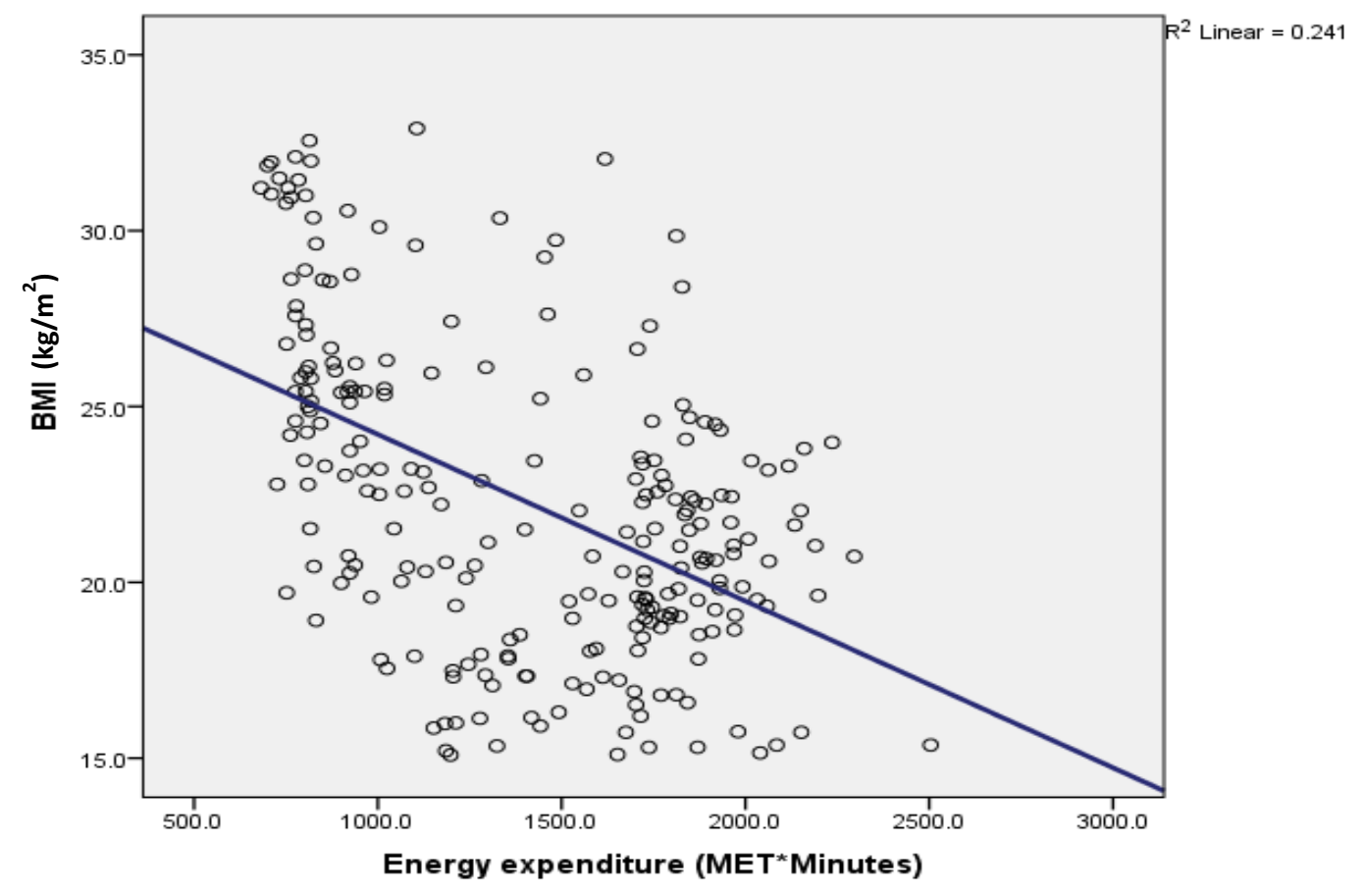

Figure 2: The association between energy expenditure and BMI $(n=300)$

\section{CONCLUSIONS}

The prevalence of underweight remains a major nutritional problem among adolescent school children in the Ratnapura district, while overweight and obesity are increasing at an

\section{REFERENCES}

Ainsworth, B.E., Haskell, W.L., Herrmann, S. D., Meckes, N., Bassett, D. R., Tudor-Locke, C., Greer, J. L., Vezina, J., Whitt-Glover, M. C. and Leon, A. S. (2011). 2011 Compendium of Physical Activities. Medicine and Science in Sports and Exercise, 43(8), 1575-1581.

Antony M. and Bhatti R.K. (2015). Junk Food Consumption and Knowledge about its Ill Effects among Teenagers: A Descriptive Study. International Journal of Science and Research, 4(6), 1133-1136.

Askari Majabadi, H., Solhi, M., Montazeri, A., Shojaeizadeh, D., Nejat, S., Khalajabadi Farahani, F.and Djazayeri, A. (2016). Factors Influencing Fast-Food Consumption Among Adolescents in Tehran: A Qualitative Study. Iranian Red Crescent Medical Journal, 18(3), 79. alarming rate. There was a negative relationship between the BMI of students and their physical activity. A high percentage of students who consumed junk food as their breakfast suffered from overweight and obesity conditions.

Bauman, A., Bull, F., Chey, T., Craig, C. L., Ainsworth, B. E., Sallis, J. F., Bowles, H. R., Hagstromer, M., Sjostrom, M., Pratt, M. and Group, I. (2009). The International Prevalence Study on Physical Activity: results from 20 countries. International Journal of Behavioral Nutrition and Physical Activity, 6(1), 21.

Behzad D., Sahand R, and Maryam-Hajian, A.R. (2015). Assessment of the Situation and the Cause of Junk Food Consumption in Iran and Recommendation of Interventions for Reducing its Consumption. Community Health, 2(3), 193204.

Boylan, S., Hardy, L. L., Drayton, B. A., Grunseit, A. and Mihrshahi, S. (2017). Assessing junk food consumption among Australian children: trends and associated characteristics from a cross-sectional study. BMC Public Health, 17(1), 299.

de Wilde, J. A., van Dommelen, P., van Buuren, S. and Middelkoop, B.J.C. (2015). Height of South Asian 
children in the Netherlands aged 0-20 years: secular trends and comparisons with current Asian Indian, Dutch and WHO references. Annals of Human Biology, 42(1), 38-44.

Fernández Morales, I., Aguilar Vilas, M. V., Mateos Vega, C. J. and Martínez Para, M. C. (2011). Breakfast quality and its relationship to the prevalence of overweight and obesity in adolescents in Guadalajara (Spain). Nutricion Hospitalaria, 26(5), 952-958.

Godakanda, I., Abeysena, C. and Lokubalasooriya, A. (2018). Sedentary behavior during leisure time, physical activity and dietary habits as risk factors of overweight among school children aged 14-15 years: case control study. BMC Research Notes, 11(1), 186.

Hajian-Tilaki, K. and Heidari, B. (2013). A Comparison between International Obesity Task Force and Center for Disease Control References in Assessment of Overweight and Obesity Among Adolescents in Babol, Northern Iran. International Journal of Preventive Medicine, 4(2), 226-232.

Katzmarzyk, P. T. (2008). Obesity and Physical Activity Among Aboriginal Canadians. Obesity, 16(1), 184-190.

Kearns, K., Dee, A., Fitzgerald, A. P., Doherty, E. and Perry, I. J. (2014). Chronic disease burden associated with overweight and obesity in Ireland: the effects of a small BMI reduction at population level. BMC Public Health, 14(1), 143.

Kesäniemi, A., Riddoch, C. J., Reeder, B., Blair, S. N. and Sorensen, T. I. (2010). Advancing the future of physical activity guidelines in Canada: an independent expert panel interpretation of the evidence. International Journal of Behavioral Nutrition and Physical Activity, 7(1), 41.

Kowalski, K.C., Crocker, P.R.E., Columbia, B. and Donen, R.M. (2004). The Physical Activity Questionnaire for Older Children (PAQ-C) and Adolescents ( PAQ-A ) Manual. Coll. Kinesiol. Univ. Sask., 87, 1-38.

Ministry of Healthcare and Nutrition. (2010). National Nutrition Policy of Sri Lanka. Ministry of Healthcare and Nutrition, Sri Lanka.

Mistry, S. K. and Puthussery, S. (2015). Risk factors of overweight and obesity in childhood and adolescence in South Asian countries: a systematic review of the evidence. Public Health, 129(3), 200-209.
Montoye, A. H., Pfeiffer, K. A., Alaimo, K., Betz, H. H., Paek, H.-J., Carlson, J. J. and Eisenmann, J. C. (2013). Junk Food Consumption and Screen Time: Association with Childhood Adiposity. American Journal of Health Behavior, 37(3), 395-403.

Popkin, B. M., Horton, S. H. and Kim, S. (2001). The nutrition transition and prevention of dietrelated diseases in Asia and the Pacific. Food and Nutrition Bulletin, 22(4 SUPPL.), 54-58.

Ridley, K., Ainsworth, B. E. and Olds, T. S. (2008). Development of a Compendium of Energy Expenditures for Youth. International Journal of Behavioral Nutrition and Physical Activity, 5(1), 45.

Robert J K., Cynthia L O., Shumei S G., Laurence M,, Katherine M. F., Zuguo M., Rong W., Lester R C., and Alex F.R. C. L. J. (2002). 2000 CDC Growth Charts for the United States: Methods and Development. Vital Health Stat 11, 246, 1-190. https://doi.org/10.1590/S151635982002000600018

Somasundaram, N., Ranathunga, I., Gunawardana, K., Ahamed, M., Ediriweera, D., Antonypillai, C. N. and Kalupahana, N. (2019). High Prevalence of Overweight/Obesity in Urban Sri Lanka: Findings from the Colombo Urban Study. Journal of Diabetes Research, 2019, 1-9.

Tin, S. P. P., Ho, S. Y., Mak, K. H., Wan, K. L. and Lam, T. H. (2011). Lifestyle and socioeconomic correlates of breakfast skipping in Hong Kong primary 4 schoolchildren. Preventive Medicine, 52(3-4), 250-253.

Waters, E., Ashbolt, R., Gibbs, L., Booth, M., Magarey, A., Gold, L., Kai Lo, S., Gibbons, K., Green, J., O'Connor, T., Garrard, J. and Swinburn, B. (2008). Double disadvantage: the influence of ethnicity over socioeconomic position on childhood overweight and obesity: findings from an inner urban population of primary school children. International Journal of Pediatric Obesity, 3(4), 196-204.

Wickramasinghe, V., Lamabadusuriya, S., Atapattu, N., Sathyadas, G., Kuruparanantha, S. and Karunarathne, P. (2010). Nutritional status of schoolchildren in an urban area of Sri Lanka. Ceylon Medical Journal, 49(4), 114.

World Health Organization. (2010). Global Recommendations on Physical Activity for Health. https://www.who.int/publications /i/item/9789241599979 
World Health Organization. (2013). Physical status: the use and interpretation of anthropometry. https://www.who.int/gho /publications/world_health_statistics/EN_WH S2013_Full.pdfi

World Health Organization. (2005). Preventing chronic diseases: a vital investment. 2005. https://www.who.int/chp/chronic_disease_re port/contents/en

World Health Organization. (2014). Global Status Report on Non-communicable Diseases 2014. https://www.who.int/nmh/publications/ncdstatus-report-2014/en 